\title{
Julia Atzeroth: The First Coffee Producer in the Continental United States ${ }^{1}$
}

\author{
Fernando E. Vega ${ }^{2}$
}

\begin{abstract}
Julia Atzeroth, a German woman who immigrated to the USA and settled in Florida during the 1840's, was the first coffee producer in the continental United States.
\end{abstract}

Key Words: Julia Atzeroth, coffee, Coffea arabica L., Rubiaceae, Florida (USA), history

During a visit to the Academy of Natural Sciences of Drexel University in Philadelphia, Pennsylvania (USA), a herbarium specimen with historical significance (Figure 1) was brought to the author's attention. The specimen was taken from the first coffee plant (Coffea arabica L., Rubiaceae) in the continental United States to produce coffee, as indicated by the inscription below the specimen, which reads as follows:

\section{Coffee-Tree (Coffoea Arabica).}

The tree from which this branch was obtained was grown by Madam Julia Atzeroth near Braidentown, Florida, and is the Tree that produced under her culture the first pound of Coffee raised in the United States. She received from the Commissioner of Agriculture at Washington Ten dollars as a premium therefor in $1880^{3}$ after four years growth from seed procured from Cordova in Mexico. Branch showing leaves, flowers and fruit culled by her own hand 5 mo. 13. 1885. Tree a vigorous grower, about eleven feet high, branching thickly from a short trunk and bearing flowers and fruit in profusion. Madam Atzeroth is a Bavarian lady, and at the time given about 78 yrs of age.

Julia Hunt was born in Bavaria, Germany, on December 25, 1807, and at the age of 24 married Joseph Atzeroth, with whom she immigrated to the United States in 1841, moving to Florida in 1843 and to Fogartyville (part of Bradenton in Manatee County on the Gulf Coast) in 1873 (Upham 1881). The coffee plant referred to in the inscription was planted in 1876 by Mrs. Atzeroth (Figure 2) in her four-acre garden, using a "few grains of Mexican coffee" that had been given to her by Mrs. E. S. Warner, her neighbor, who had received them from A. A. Russell, a resident of Córdoba in the state of Veracruz, Mexico (Upham 1881).

\footnotetext{
${ }^{1}$ Submitted on December 20, 2014. Accepted on December 22, 2014. Last revisions received on December 29, 2014.

${ }^{2} 14609$ Pebblestone Drive, Silver Spring, Maryland 20905 USA. E-mail: trainofstories@ gmail.com

${ }^{3}$ Last digit illegible but presumed to be 1880 .
}

DOI: 10.9784/LEB2(4)Vega.01

Electronically available on January 10, 2015. Mailed on January 10, 2015. 


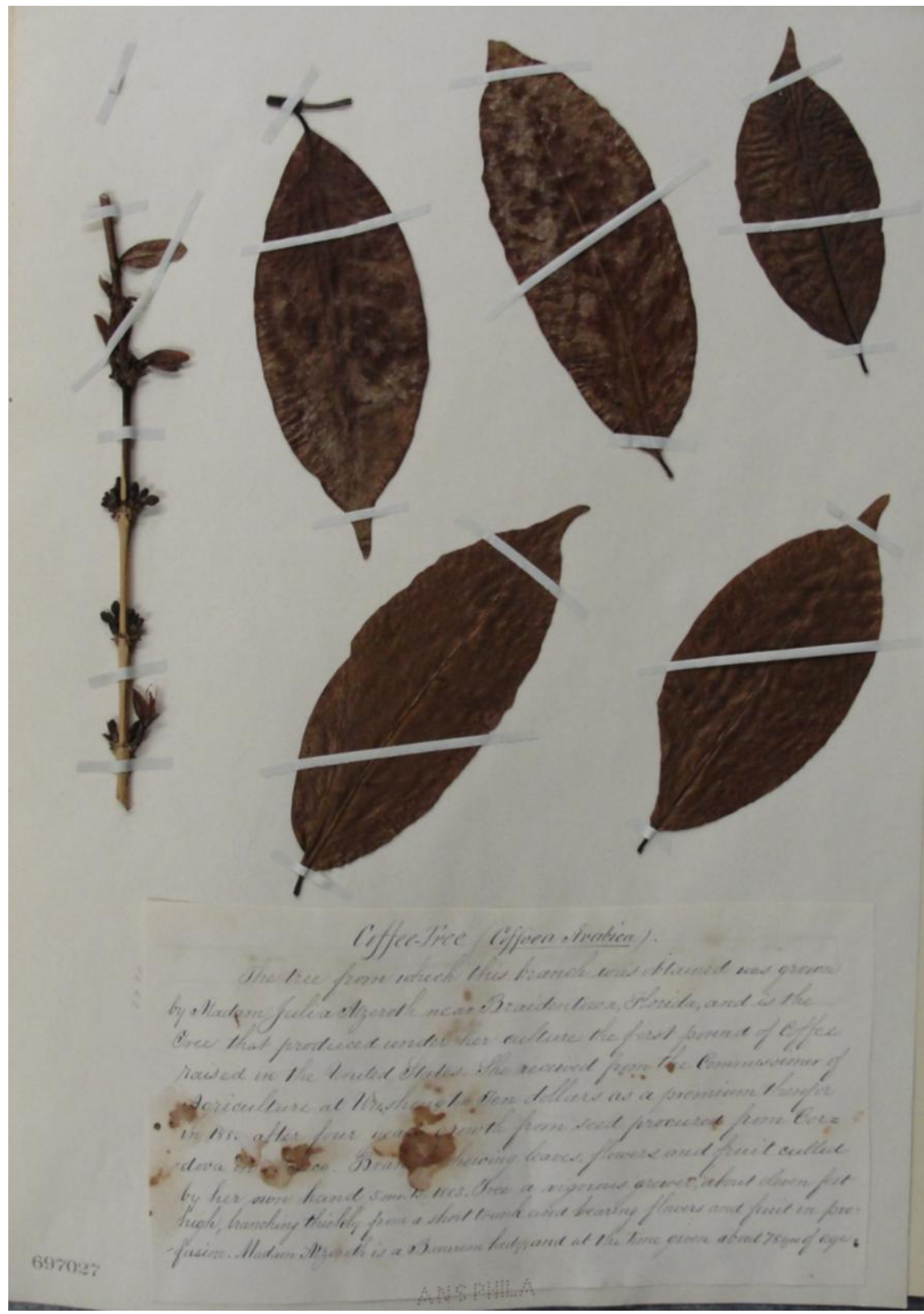

Figure 1. Herbarium specimen of the first coffee plant to produce coffee in the continental United States. Specimen \#697027 at the Herbarium of the Academy of Natural Sciences of Drexel University in Philadelphia, Pennsylvania (USA). 


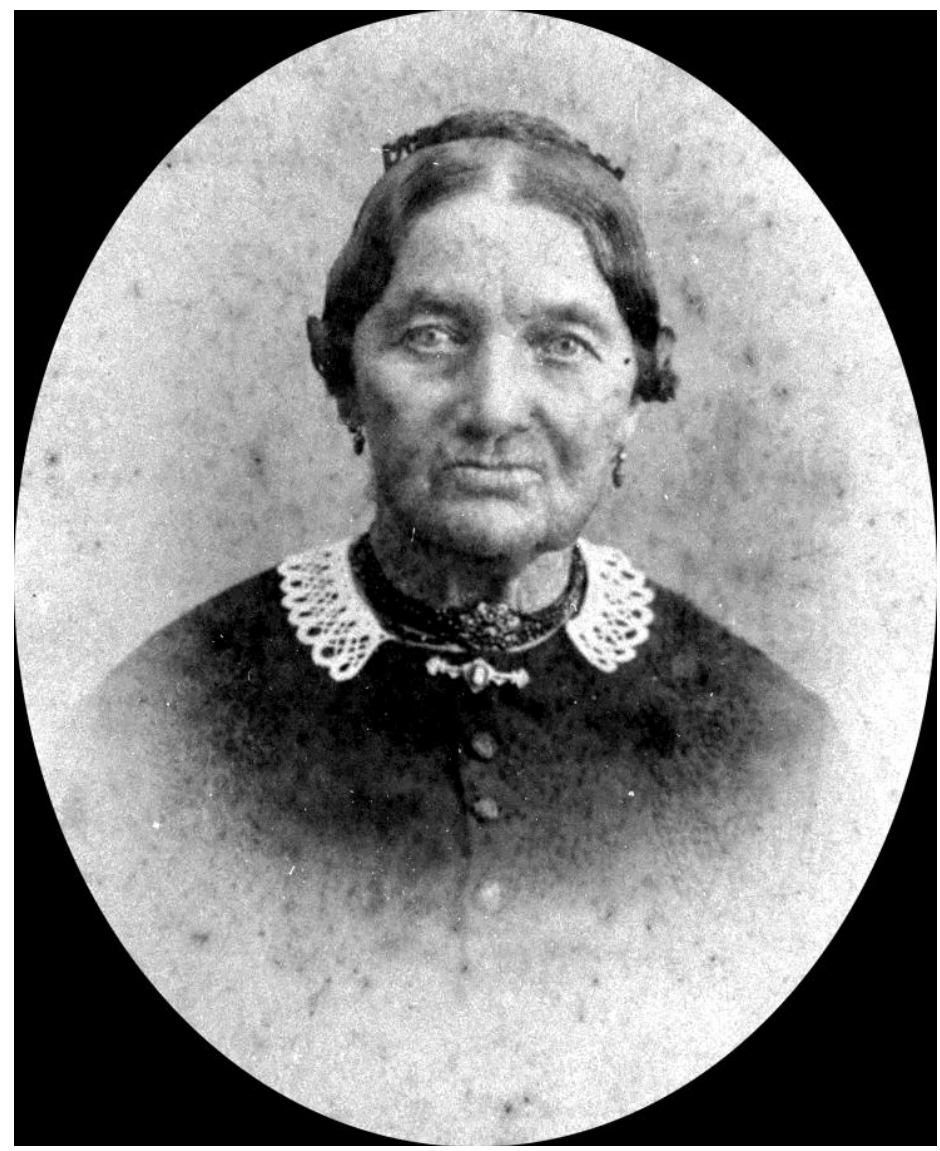

Figure 2. Madame Julia Atzeroth at 80 years of age. Photo taken on her birthday, December 25, 1887. Photo courtesy of the Manatee County Public Library Historical Image Digital Collection, Florida (USA).

The "premium" mentioned in the inscription was not really a "premium" but payment for the seed, as explained by Saunders (1883:28): "Being familiar with the transaction that led to its origin, I took occasion to correct any erroneous impressions which were evidently popularly connected with it. In the first place, the Government never offered any premium for coffee. A package of fresh coffee berries was sent to the Department of Agriculture, under the impression that a premium had been offered by it for such a product, and as fresh coffee seed is rather difficult to procure, and was required by the Department, these were purchased and paid for as a matter of course."

Mrs. Atzeroth coffee shipment was accompanied by a letter addressed to William Gates Le Duc, Commissioner of the Department of Agriculture during 
the Administration of President Rutherford B. Hayes (1877-1881). The letter, published in 1879 , includes interesting commentary on the suitability of coffee in Florida: "I feel sure it can be successfully grown further south where frost never comes, and there is an abundance of land and soil suited to its growth" (Anonymous 1879:1136-1137). In the spring following the one-pound shipment, Mrs. Atzeroth sent the Department of Agriculture an additional four pounds of coffee harvested from two plants in her garden (Upham 1881). Even though Upham (1881) states that the first pound of coffee was sent to the Commissioner on February 20,1880, this cannot be correct based on the letter published in 1879.

The 1880 Annual Report of the Commissioner of Agriculture stated, "A large distribution of coffee-plants has been made in Florida and southern California" (Anonymous 1881:17), which was an attempt to determine whether coffee could be commercially viable in the United States. A frost in 1886 badly damaged all the coffee trees on Mrs. Atzeroth's property as well as many other coffee plants that had been planted elsewhere in south Florida, leading to the following conclusion: "It is probable that the culture of coffee could be made profitable on the extreme southern part of the main-land and on the lower range of keys, but unless artificial shelters are constructed the plant is too tender for extensive culture north of the Caloosahatchee" (a river in the southwest Florida Gulf Coast) (Anonymous 1891:55). Despite Mrs. Atzeroth's efforts, coffee plantations have never been viable anywhere in the continental United States, and have only been commercially feasible in Hawaii and Puerto Rico. Mrs. Atzeroth was 94 years old when she passed away on January 24, 1902; she is buried at the Fogartyville Cemetery in Bradenton, Florida.

\section{Literature Cited}

Anonymous. 1879. Message from the President of the United States to the two houses of Congress at the commencement of the second session of the Forty-sixth Congress, with the reports of the heads of departments and selections from accompanying documents. Government Printing Office. Washington, USA. $1150 \mathrm{pp}$.

Anonymous. 1881. Annual report of the Commissioner of Agriculture for the year 1880. Government Printing Office. Washington, USA. 672 pp.

Anonymous. 1891. U. S. Department of Agriculture, Division of Pomology, Bulletin No. 1. Report on the condition of tropical and semi-tropical fruits in the United States in 1887. Government Printing Office. Washington, USA. 149 pp.

Saunders, W. 1883. Observations on the soils and products of Florida. Special report no. 62, United States Department of Agriculture. Government Printing Office. Washington, USA. 30 pp.

Upham, S. C. 1881. Notes from Sunland, on the Manatee River, Gulf Coast of South Florida. Its climate, soil and production. Published by the author. Braidentown, Florida, USA. 83 pp. https://archive.org/details/notesfromsunland00upha 